\title{
Urdimento
}

Revista de Estudos em Artes Cênicas

E-ISSN: 2358.6958

\section{Cidades em precipício: das fronteiras sensíveis on e off-line}

Altemar Gomes Monteiro

Mônica Medeiros Ribeiro

\section{Para citar este artigo:}

MONTEIRO, Altemar Gomes; RIBEIRO, Mônica Medeiros. Cidades em precipício: das fronteiras sensíveis on e off-line. Urdimento, Florianópolis, v. 2, n. 38, ago./set. 2020.

DOI: http:/dx.doi.org/10.5965/14145731023820200021

Este artigo passou pelo Plagiarism Detection Software | iThenticate 


\title{
Cidades em precipício: das fronteiras sensíveis on e off-line ${ }^{1}$
}

\author{
Altemar Gomes Monteiro²
}

Mônica Medeiros Ribeiro ${ }^{3}$

\section{Resumo}

Os autores apresentam neste texto uma reflexão sobre forças poéticas e políticas envolvidas na cena teatral imersa no contingente evidenciado pela pandemia da COVID-19. Das ruas e dos teatros possíveis nesse contexto, objetivam pensar acerca das cidades que por hora emergem nos imaginários vivenciados na fronteira on e offline, seja pelos processos de composição em arte que se viram forçados a migrar para a internet, seja pelo lastro deixado pelos meios de comunicação num mundo hiperconectado. Por meio do diálogo com Néstor Garcia Canclini e outros pensadores da cena contemporânea, os autores constatam o entrelaçamento entre o que aqui chamam de cidades online e cidades offline e apontam desafios poéticos que se erguem nos debates sobre o tempo-espaço dentro e fora da internet. 0 que restará de nossos teatros em meio a uma pandemia da informação? Defendendo uma expansão do sensível, partem da cena contemporânea para pensar que outros corpos e espacialidades estão sendo exigidos ou impostos no torvelinho da guerra biopolítica que nos circunda.

Palavras-chave: Cidades Online. Cidades off-line. Teatro contemporâneo. Internet.

\footnotetext{
1 O presente trabalho foi realizado com apoio da Coordenação de Aperfeiçoamento de Pessoal de Nível Superior - Brasil (CAPES) - Código de Financiamento 001- junto ao Programa de Pós-graduação em Artes da UFMG

Encenador, dramaturgo, diretor fundador do Nóis de Teatro, grupo atuante há 18 anos na periferia de Fortaleza. Doutorando em Artes da Cena pela UFMG, Bolsista PROEX CAPES, pesquisa as relações entre corpo e cidade nas tessituras poéticas do teatro de rua contemporâneo e suas interfaces com as experiências de cidade imprimidas pelas periferias urbanas e suas negritudes. altemargm@yahoo.com.br

${ }^{3}$ Artista de dança e atriz, Doutora em Artes. Professora do Departamento de Artes Cênicas e da Pós-graduação em Artes da UFMG. monicaribeiro@yahoo.com
} 


\title{
Cities in precipice: on sensitive frontiers on and offline
}

\begin{abstract}
The authors present in this text a reflection on poetic and political forces involved in the theater scene immersed in the contingent evidenced by the pandemic of COVID-19. From the streets and theaters possible in this context, they aim to think about the cities that emerge for the time being in the imaginary experienced on the on and offline frontier, either by the processes of composition in art that were forced to migrate to the internet or by the ballast left by the media of communication in a hyperconnected world. Through the dialogue with Nestor Garcia Canclini and other thinkers of the contemporary scene, they note the fusion operated between what they call online cities and offline cities here to think about the poetic challenges that arise in the debates about time-space inside and outside the internet. What will be left of our theaters in the midst of an information pandemic? Defending an expansion of the sensitive, they leave the contemporary scene to think that other bodies and spatialities are being demanded or imposed in the midst of the turmoil of the biopolitical war that surrounds us.
\end{abstract}

Keywords: Online Cities. Offline cities. Contemporary theater. Internet. 
As cidades também acreditam ser obra da mente ou do acaso, mas nem um nem o outro bastam para sustentar suas muralhas. De uma cidade, não aproveitamos as suas sete ou setenta e sete maravilhas, mas a resposta que dá às nossas

perguntas.

(ítalo Calvino).

A rua é um precipício. Um abismo que nos chama e invade recantos íntimos da existência. Essa rua, também fronteiriça, tem habitado nossos sonhos de retomada desse lugar de invenção de mundos os mais diversos. Daqui de onde escrevemos, nesse vai e vem de troca de e-mails e aplicativos de reuniões virtuais, olhamos da janela para o que desde sempre nos abisma - a rua - imaginando, desejando e sonhando o que acontece lá fora. Se tornaram elas ermas de sentido? Onde foram parar as memórias das festas e teatros que hoje acontecem na internet - online? Que novos acordos e acordes estão sendo tracejados nas composições com o urbano? O que nos espera nas promessas de tantos futuros previstos e imaginados?

Composições com o urbano proliferam nas redes, redesenhando cidades em sua nova configuração virtual e levando-nos a pensar que há mais cidades na cidade, há mais rua nas casas e mais cena nas redes. As cidades que entretecem ruas, vielas, esquinas, avenidas, existências, sombras, luzes, concreto deixam ainda mais evidente sua natureza fronteiriça. Cássio Hissa nos diz desse espaço feito de experiências de aproximações e afastamentos, de conflitos e diálogos: "A cidade é feita de passagens. [...] a cidade é fronteira”. (Hissa, 2008, p.269).

A noção de fronteira, conforme Cássio Hissa (2002; 2006), se distingue da noção de limite, uma vez que estaria voltada para fora dos territórios e o limite para dentro desses. "O limite estimula a ideia sobre a distância e a separação, enquanto a fronteira movimenta a reflexão sobre o contato e a integração. Entretanto, a linha que separa os conceitos é espaço vago e abstrato. (Hissa, 2006, p. 34)." Compreendida como espaço de trânsito, a fronteira é habitada por fluxos que encaminham diálogos, é espaço afeito a misturas. O limite que promove a cisão, a diferença abissal entre pares dicotômicos como dentro e fora, casa e rua, 
cidade online e offline, não cabe, portanto, na compreensão que ora propomos de fronteira. Interessa-nos, desse modo, pensar a cidade como esse espaço de passagens, fluxos que operam na abertura para o diálogo, para as interpenetrações e entrelaçamentos entre territórios.

O perigo iminente, presente na expressão em precipício, coloca o território da cidade em estado de alerta, na vertigem de um desequilíbrio. Nesses tempos do agora ${ }^{4}$, tempos de medo e restrição, parece surgir um limite artificial entre a experiência na internet, online, e a experiência fora da internet. Nova dicotomia emerge com força - online e offline -, e parece impactar nossa ideia de cidade, território de fronteira, na medida em que também parecem se distinguir radicalmente os espaços da casa e os espaços da rua. Assim, o presente artigo especula junto à força poética de quem está diante de um precipício: na vertigem da divisão abissal entre o público e o privado, entre a casa e a rua, entre online e offline.

Do outrora ao agora, do agora ao que vem, da casa à cidade, da cidade à rua, da rua ao teatro, encaminhamos a presente reflexão acerca das cidades que por hora emergem para imaginar os possíveis do teatro nesses tempos de pandemia. Talvez, por isso mesmo, seguimos o rastro de notícias e entrevistas feitas com artistas e pesquisadores no contexto pandêmico, colocando-os em diálogo com reflexões tecidas em outros cenários. Tal escolha não é feita para traçar profecias, daquelas que operam sobre o presente produzindo passividade e submissão ao futuro, ou elogiar visionários, como aqueles que já anunciavam o que vivemos. Apostamos na reflexão sobre as composições provocadas pelo precipício que nos expecta, nos circunda e nos conclama: a rua em sua maior potência de vida, que se faz na vivência dialógica e fronteiriça, operada entre o que aqui chamaremos de cidades online e cidades offline.

É importante reiterar que essa distinção é tramada não para oferecer estofo para uma ótica dualista (on versus off), mas para promover o debate acerca dos

${ }^{4} \mathrm{O}$ agora é aqui compreendido a partir de Husserl indicando o horizonte temporal da vivência (Abbagnano, 2018). Assim, não se trata de um presente preciso do instante, e sim vinculado às experiências dos sujeitos na temporalidade da vivência. 
traçados poéticos e políticos que se erguem frente ao contingente aguçado pela pandemia. O que restará de nossos teatros no meio de uma outra pandemia: a da informação? Diante da hiperconexão virtual, haveria ainda espaço para estar vivo na rua? Que ruas são possíveis de serem vividas e tracejadas na internet? Haveria espaço público nas malhas de um algoritmo? Que outros corpos e espacialidades estão sendo exigidos em meio ao torvelinho da guerra biopolítica que nos circunda? Ainda nos é possível optar por estar on ou offline?

O corpo e a cidade parecem nunca ter estado em tamanha evidência, agenciando disputas acirradas no campo da ciência, das teorias do urbanismo às patentes da biologia. Entretanto, o que se anuncia no desenho ensaiado neste artigo é, mais que nunca, a reflexão sobre nosso gesto de composição em arte a partir do que se evidencia nas dinâmicas imbricadas pelo on e offline do espaçotempo que vivemos. O desafio que se ergue nesse tecido de territórios on-offevoca a urgência de uma expansão do sensível, levando-nos a apostar na potência da arte na construção de corpos e cidades que nos tirem da inércia de espanto para imaginar práticas vitalistas que toquem no que ainda soa inconcebível.

Reiteramos o entrelaçamento entre as dimensões on e off das cidades, ainda que apareçam separadas no texto que segue. Essa separação, de natureza artificial, evidencia, paradoxalmente, a natureza fronteiriça da constituição da cidade desses tempos, território para as artes da cena.

\section{Cidades online}

As cidades também são fundadas dentro dos livros.

(Rosalba Campra)

A fibra ótica tocou no íntimo do que entendíamos como biopolítica. Não seria devaneio se juntar ao coro dos que anunciam o smartphone como um novo membro do corpo do homem e da mulher contemporâneos, que subjetividades e afetos estão sendo cabeados e que neurotransmissores estão conectados via wifi. Cabe, então, pensarmos em que tipo de corpos e cidades estão sendo evocados 
no contexto da pandemia e o que uma vida online dispara nos processos de imaginação do urbano. Para isso, de início, pegamos de empréstimo o texto de Tim Ingold para assumir seu chamado de trazer a imaginação de volta à vida, tirandoa do plano de um pretenso irreal para concebê-la como processo de estar vivo:

Devemos dispensar, de uma vez por todas, a convenção de que a imaginação consiste no poder de produzir imagens, ou de representar as coisas em sua ausência. [...] devemos reconhecer no poder da imaginação o impulso criativo da própria vida gerando continuamente as formas que encontramos, seja na arte, através da leitura, escrita ou pintura, ou na natureza, através da caminhada na paisagem. (Ingold, 2015, p. 299).

Ao concordarmos com Ingold que a imaginação mais que representar ausências produz formas, podemos vivenciar a internet de modo a perceber que além de um imperativo de hiperconectividade, seu ciberespaço, agora de maneira incessante, não só fabrica, mas também convoca, novos corpos e cidades. Imaginar possíveis corpos, gestos que compõem cidades, encaminha processos de transformação de si e do outro, tão caros às artes da cena. A cidade dos livros, dos jornais, as cidades da internet são, portanto, resultados da operação imaginativa de corpos que criam com restos, atualizando memórias, em movência contínua.

Nestor Garcia Canclini já concordava, no início dos anos 2000, que a indústria da comunicação está completamente vinculada aos processos de composição do urbano, alertando-nos que os meios de comunicação não são apenas redes invisíveis e deslocalizadas, de domínio exclusivo das estratégias empresariais, mas que operam na remodelação dos imaginários urbanos. Há, na teia complexa da telemática, forças mobilizadoras que tocam no "real" da vida pública e urbana. Os imaginários estabelecidos pela indústria da imagem, pelas correntes e memes espalhados via whatsapp, pelas vinte e quatro horas de stories veiculados no Instagram, não apenas falam do poder daquela "sociedade do espetáculo" debordiana - o que em si já ergue uma crítica de grande importância -, mas também nos dizem do modo como a vida pública, como conhecíamos antes, está sendo, talvez agora ainda mais, desenhada por subjetividades e corpos online. "A tão referida ação transformadora das indústrias culturais deve ser redimensionada 
e requalificada à luz destes estudos que problematizam, com uma nova perspectiva, as funções dos meios de comunicação” (Canclini, 2002, p. 50). Mesmo o que, em outros cenários, poderia ser chamado de "ativismo de poltrona", parece hoje tomar outros contornos se atentarmos para a força política que o twitter suplanta ao mobilizar toda uma opinião pública sobre uma pauta específica.

Estar na internet já é condição incontornável. Da transmissão ao vivo, gesto até então de domínio exclusivo das grandes redes de televisão, até a possibilidade de um texto no Facebook ser mais lido do que uma manchete no jornal, não estaríamos falando sobre uma vida pública que se opera, tão ou mais presente, nos algoritmos e engajamentos do chamado "vale do silício"? Se antes Canclini (2002) assumia que os relatos mais influentes sobre o que significa a cidade emergiam da imprensa, do rádio e da televisão, não haveria surpresa alguma em admitir que, com a expansão dos meios de comunicação e a incontornável vida online que se instaura com a pandemia, é na internet que estão sendo imaginadas, tecidas e escritas as cidades. Por que então não assumirmos que as cidades imaginadas na internet estão também compondo as formas do mundo?

Os modos de uso da cidade, as possibilidades de construção de afeto, política, polícia, economia e cultura estão intimamente relacionadas ao que se fabula, imagina, escreve, desenha dentro de casa, ali mesmo no tablet ou no celular. "As cidades da era da vídeo-cultura ou do ciberespaço são situadas em um âmbito incomensurável, em um conjunto de redes e fluxos existentes tanto no mundo físico como no mental" (Canclini, 2002, p. 44). Se assumirmos, então, o poder operado pela indústria da cultura, no chamado capitalismo cognitivo $^{5}$, iremos admitir que mais do que na literatura ou nas manchetes jornalísticas que descrevem e fundam o urbano, há algo de muito violento e sedutor operando entre

\footnotetext{
${ }^{5}$ A noção de Capitalismo Cognitivo, também chamada de "Capitalismo Cultural" ou de "Capitalismo Estético" (Lazaratto, 2006; Negri; Hardt, 2005) emerge com o avanço da Rede Mundial de Computadores, fenômeno que opera uma mudança nas ideias de capital e consumo já que no seu cerne está o trabalho imaterial e cognitivo como força de produção. A obra de Michel Hardt e Antonio Negri (2005) se apresenta de grande importância para esse estudo no que tange à noção de comum já que, para os autores, essa fase do capitalismo se apropria justamente de uma "inteligência coletiva”. Para Isabelle Stengers (2015, p. 80), "[...] o capitalismo 'cognitivo' não se apropria do inapropriável, mas destrói (continua a destruir) o que constitui comunidade. O 'comum', aqui, não tem de modo algum os traços de uma espécie de universal humano, garantia (conceitual) de um além das oposições. Ele é o que reúne commoners, o que com frequência se traduz por 'usuários"'.
} 
as virtualidades de corpos que movem o mundo dentro de casa, pela palma da mão. E sabemos do quanto o poder oficial não só entendeu como colocou em prática essa máxima: o resultado das eleições presidenciais no Brasil em 2018 nos provam essa tomada de decisão pela qual a performatividade do marketing sai da recepção e transforma-se em sugestão, operando de modo compulsório sobre subjetividades.

Consideramos, entretanto, que não será com os mesmos imaginários de sempre que nós, corpos entreabertos nas templates de windows codificados, vamos conseguir erguer novas experiências de mundo. Haveria, agora mesmo, aqui entre nós, algo que desative a repetição embrutecida do estímulo desenfreado do trabalho empreendedor de si, da promessa da celebridade blogueira, do sucesso embebecido dos likes ou mesmo do cálculo milimétrico de algoritmos que garantam a continuidade do status quo? Qual o sentido de idealizar esse mover do mundo a partir da internet sem levar em consideração que estamos num espaço onde não apenas os dados são vendidos e negociados por grandes corporações, mas que essas mesmas mobilizam, a sua guisa, qual conteúdo será acessado e por quem será veiculado, a que horas e em que lugar? Canclini já parecia entender bem isso ao nos alertar que os meios de comunicação contribuem para reproduzir, mais do que para alterar, a ordem social. Se a ótica de Canclini se ateve à tv e ao rádio, a internet hoje nos comprova que também:

Seus discursos têm uma função de mimese, de cumplicidade com as estruturas sócio-econômicas e com os lugares comuns da cultura política. Mesmo quando registram manifestações de protesto e testemunham a desigualdade, editam as vozes dissidentes ou excluídas de maneira a preservar o status quo. As cidades são imaginadas pelos meios de comunicação como lugares onde as transformações acabam sendo absorvidas pela normalidade, e tudo que ultrapassa ou rompe a ordem urbana é reconstituído, em última instância, pelas sínteses informativas midiáticas. (Canclini, 2002, p. 50).

Assim, mesmo o massmédia operado por mídias alternativas ou ciberativistas que haqueiam grandes corporações e operam com mudanças significativas nessas absorções normativas, nos levam a pensar que o que está em jogo nessas disputas é da ordem de meios de produção (no sentido marxista) muito maiores do que o 
que nós, artistas da cena, dispomos rotineiramente em nosso fazer. Nesse sentido, ao que parece, o que nós, artistas da cena, estamos boquiabertos tentando aprender é que o agora nos impôs não somente o conflito biopolítico agenciado por um vírus, mas também nos conduziu ao mal estar de tentar compreender a internet por sua espacialidade - conceito tão caro ao nosso fazer. Não é raro ouvirmos discursos inflamados de vozes avessas às lives e o sufoco gerado pela grade efusiva de programações online. Compreendemos que a negativa de uso da internet traz em si algo que tensiona a exigência normatizada rapidamente pela economia da cultura. No entanto, essa crítica precisaria decantar o incômodo para se ater ao desafio desse labirinto, sob a pena de perder a oportunidade de, mesmo na internet, imaginar outras espacialidades e tensionar as lógicas de composição do mundo operadas pelo ciberfascismo.

As alternativas disputadas na cena contemporânea imersa na pandemia evocam uma espécie de espacialidade que, mais que tocar na dimensão do ciberespaço - ideia cunhada por William Ford Gibson na década de 1990 —, dizem respeito a toda uma cidade que se tece junto à performatividade também constituinte da internet. Ao sermos impelidos para fora da rua ${ }^{6}$ - espaço de criação de cidades e mundos - , de volta à casa, corremos para as redes de silício, adaptando, como pudemos, nossos modos artísticos para nos apropriarmos da linguagem da internet, que muitos, anteriormente, não se interessavam. O teatro na internet não é novidade, mas a expressiva migração da cena teatral para esse campo de ação virtual torna urgente a discussão ampliada decorrente desse movimento, antes de exceção?

Em poucos dias, a rede foi ocupada pelos mais diversos tipos de lives - de palestras, de mesas redondas, conversas, cenas de teatro, leitura dramática, dança, vídeo-dança, teatro em vídeo e outros. A pressa para não desaparecer, para não

\footnotetext{
${ }^{6}$ Desde o final de fevereiro de 2020, os (as) brasileiros (as), e outras partes do mundo anteriormente, foram acometidos pela COVID19, provocada pela pandemia do Corona Vírus SARS- CoV -2. Diversos estados brasileiros buscaram implementar o chamado isolamento social, medida utilizada em situações de guerra ou pandemia, dada a urgência da necessidade de se conter a transmissão do vírus. Desse modo, muitos fazedores de teatro de rua, entre diversos outros artistas, deixaram seu espaço de atuação poética e se recluíram em suas casas.
}

Sobre o tema sugerimos a leitura do artigo Cena de Exceção: o teatro neotecnológico em Belo Horizonte (Brasil) e Buenos Aires (Argentina), de autoria de Mariana Muniz e Jorge Dubatti, publicado em 2018. 
perder o sentido de existir, não perder algum contato com o outro e a necessidade de se adaptar às novas lógicas econômicas e empreendedoras da internet têm promovido grande quantidade de programações para os que podem ficar em casa. Grupos e coletivos de teatro vão se dispondo a compor com o delay, com a constante queda dos sinais, com as falhas de áudio, com as possibilidades transmídia, ou mesmo com os layouts disponiveis nos aplicativos e redes sociais de reunião online. Assumindo um lugar de "não teatro", grupos, como o Galpão (MG), Os Satyros (SP) ou a Inquieta Cia(CE), se arriscam nesse plano de composição de atmosferas online tendo como base dramatúrgica o arcabouço teatral que experimentavam outrora. Trabalhos como "Éramos em Bando" ", A arte de encarar o medo" ou "Metrópole Online - Arte para alimentar"10, dos respectivos grupos acima citados, mais que compor com o ambiente online (ou das lives), disparam possibilidades para pensarmos outras táticas de produção cultural, experimentando lógicas de agendamento prévio ou de data e horário específico para exibição, operando próximo da própria mística efêmera do teatro. Entretenimento, no modo sobrevivência, que encaminha, também, possibilidades de construção de novos saberes. No entanto, esse movimento, que antes era de exceção, virou regra. Uma regra para poucos: os que puderam se adaptar ao home office $^{11}$. A migração para esse outro território, que aqui chamamos cidade online, parece ser solução, ainda que provisória, para continuarmos a existir e darmo-nos a ver. Será mesmo essa a única alternativa que temos? Não poderíamos pausar nossas ações artísticas por um tempo? Seria o silêncio uma ação de resistência à

${ }^{8}$ O filme-ensaio do Grupo Galpão (MG) foi realizado durante o período de isolamento social. Impedidos de estrear no teatro sua 25a montagem, o trabalho é resultante do encontro dos atores durante dez dias para sua primeira experiência artística virtual.

9 Sendo um dos primeiros trabalhos a entrar em temporada online no Brasil depois da quarentena, o trabalho fala de um futuro distópico, onde a pandemia se estendeu por mais de 15 anos.

10 O trabalho da companhia cearense propõe uma experiência teatral no Instagram. Silvero Pereira e Gyl Giffony performam a dramaturgia de Rafael Barbosa, outrora encenada em uma sala de teatro, de modo a utilizar as ferramentas e filtros do aplicativo como dispositivo para a encenação e a dramaturgia.

${ }^{11}$ O fenômeno de migração do trabalho para a produção remota como alternativa para diminuir o avanço da COVID19 abre o debate para densas reflexões sobre as estruturas da desigualdade. Uma parcela considerável da população brasileira, sobretudo das periferias urbanas, necessita do contato direto com a rua para negociar e fazer surgir seu sustento básico. Tal realidade nos leva a destacar o abismo socioeconômico que separa aqueles sem renda fixa, sem água potável, os que dividem poucos metros quadrados entre vários habitantes da mesma casa, daqueles que, de algum modo, podem se adaptar ao home office. As cidades, então, escancaram sua natureza fraturada. 
rápida adesão artística ao mundo digital?

Várias tarefas compositivas se impõem: compor com a câmera; compor o olhar de quem vê/assiste; compor e interagir com diálogos paralelos nos chats das lives; compor outras ruas da janela. Esses atos de criação, ainda que precocemente ensaiados, demandam imersão nessa imperativa virtualidade. Há nesse jogo cibernético, pensamos, o desejo de amenizar a ruptura dos processos vivenciados outrora no corpo a corpo da cidade onde, pelo seu caráter labiríntico, os esbarrões e tempestades do urbano nos permitiam o encontro com o que se ergue como diferente de nós mesmos.

No entanto, é preciso agudizar a intimidade mediada para construir novas possibilidades de proximidades. Reconhecendo o poder de gerenciamento de público-alvo operado pelos meios de comunicação, como Canclini já nos alertava, há de se levar em consideração que a cibercidade talvez seja bem mais previsível e controlável do que o intempestivo do urbano, lembrando-nos, inclusive dos royalties que se monetizam muito mais para grandes corporações da comunicação do que para grupos e companhias teatrais, agora migradas para a cidade online. Além disso, há que se pensar em como esses coletivos operam no gesto de composição com os aplicativos: reendossam os limites de sua doxa ou escovam a contrapelo o que nele se faz paradoxal? Reificamos o tempo-espaço presente como um limite a produzir mercadorias ou nos armamos de suas ferramentas para desenhar outros mundos possíveis? O pesquisador Pedro Bennaton, cofundador do Erro Grupo (SC), é quem nos provoca:

Uma peça gravada em uma plataforma de vídeo, uma peça sendo feita em uma transmissão ao vivo de uma rede social podem ser as últimas trincheiras da reificação do teatro como produto acabado, e a ser consumido. Sua disponibilização gratuita através de plataformas comandadas pelas grandes corporações do Vale do Silício faz com que executivos e acionistas dessas empresas lucrem e recebam em seus bilionários colos uma nova modalidade de interação nas redes: o teatro social se transformando em teatro de rede social. Talvez aí esteja o risco da morte do teatro, e não o Coronavírus ou a proibição de eventos de aglomeração de pessoas. O perigo de morte do teatro pode estar nessa solução rápida feita na ansiedade deste momento que durará a eternidade do instante de nossas vidas. (Bennaton, 2020). 
Pensar no perigo de uma cidade online para as artes da cena, dinâmicas de convívio que necessitam sobretudo da presença viva dos corpos coabitando um mesmo espaço, significa se ater ao hiperfetiche do mundo virtual e seus riscos ascendentes e vertiginosos. No imperante tecnovívio, a ameaça é de não mais retomarmos o imprescindível convívio, ao modo de Dubatti (2011). Essa perda ontológica do teatro, ainda que temporária - assim esperamos -, abala suas estruturas e nos lança ao desejo/necessidade de proferirmos inúmeros gestos de compartilhamento com o outro, ainda que mediados pelas tecnologias.

Então, é pensando a internet como um ciberespaço que lembramos que esse espaço é tecido também por um cibertempo: o tempo, conceito imprescindível para pensar as artes da cena. Olhando a rua pela janela, vendo-a meio vazia, meio silenciosa, lembramos do tempo lento, antes esquecido na cidade da pressa. Ao olhá-la pela janela imaginamos possíveis e reiteramos que ela não está tão longe, uma vez que mora em nós, lembrando-nos da imprescindível ressalva de que a cidade online traz parcelas da cidade off-line. Cidades fronteiriças, territórios de on e off. Entretanto, ainda que entrelaçadas, surgem no agora, aparentemente, cindidas, uma vez que a cidade online é habitada por quem pode acessá-la com maior velocidade, constituindo-se associada ao progresso, à velocidade da comunicação, demandando uma humanidade veloz que, na banda larga, performa e deseja uma corporeidade 5G. Uma cidade global - que exclui as localidades que se diz para todos. Beatriz Sarlo, ao discorrer sobre o que chama de cibercidade, é quem ressalva:

Porém, como no caso da mercadoria do shopping, o fato de muitos ainda não poderem ter acesso a ela não implica que a alegoria da cibercidade não funcione para todo o mundo, exceto para quem vive muito abaixo e muito precariamente na cidade real. As imagens se generalizam antes dos fatos e operam como forças materiais que exercem pressão sobre a imaginação urbana. (Sarlo, 2014, p. 206).

As imagens reificadas na internet já são fato, sendo provável, portanto, que já não exista uma distância expressiva entre o plano da imagem fabricada na "rede social" e sua repercussão no que se entende por "vida real". Ao entender essa cibercidade como um espaço nem tanto democrático ou acessível quanto se 
apresenta, como desenhar outras internets e espaços de convívio no tecnovívio que toquem no sensível de modo a tecer outros e urgentes mundos? Para Dubatti (informação verbal)12, não há convívio no tecnovívio. Se assim for, estamos perdendo algo fulcral: o corpo a corpo, o suor, os odores, o contato das peles. No entanto, parafraseamos Canclini para perguntar: a pandemia somente nos empurra tecnologias audiovisuais ao recanto doméstico, ao esquecimento e à espetacularização da distância, ou existiriam formas de reapropriação crítica das representações midiáticas?

O filósofo italiano Franco Bernardi (Bifo), em entrevista recente ao Jornal El País, nos diz que, para elaborarmos melhor os efeitos da pandemia de uma maneira menos dolorosa,

precisamos de uma elaboração coletiva, utilizando-nos de sinais, gestos linguísticos, sugestões subliminares, convergências subconscientes. E isso se dá propriamente no espaço da poesia, uma vez que ela é o campo em que novas disposições de sensibilidade podem ser moldadas. (Bernardi, 2020).

O mesmo autor nos fala que uma explosão poética está sendo mobilizada na internet, sob uma "forma refinada de minério" que fervilha como espaço de potência de solidariedade e libertação. O fato de milhões de pessoas estarem usando a internet para imaginar suas cidades faz com que o filósofo acredite que, em uma enorme escala, uma pesquisa coletiva esteja em andamento, "uma pesquisa que é simultaneamente psicanalítica, política e estética” (Bernardi, 2020). Pode bem ser que Bifo recaia num idealismo que acredita que "A revolução será TickTockeada”, imperativo que mal nos dá tempo para avaliar, de modo profundo, os custos psíquicos inclusos nessa jornada coletiva online. Mas o que ele nos leva a considerar, e sem medo algum de estarmos nos precipitando, é que, talvez, estejamos "passando por uma máquina de escrever que tenta reativar a sensibilidade" (Bernardi, 2020), mesmo dentro do rolo compressor da hiperconexão.

Um tipo de estética está em composição, e nós artistas estamos tentando

12 Palestra proferida no Fórum de Estágios - Docência em Teatro - 1ª Edição/2020. Em 14 de agosto de 2020. 
encontrar nossa participação no meio disso, o que nos leva a uma complexa teia de questionamentos, laboratórios e testes para que efetivemos algum tipo de movimento que não recaia somente nesse imperativo migratório, mas num gesto estético, político e emancipador, que tem sua maior potência no que nos resta de imaginação.

\section{Cidades offline}

Qual é a escrita das cidades que nos devolve o lugar das palavras de encontro?

(Cassio Hissa e Carla Wstane)

O desejado gesto estético, político e emancipador não estará eternamente confinado nos domínios da vida doméstica, desejamos. É na cidade praticada por um corpo a corpo de suor, sangue e lágrima que a composição com a cidade tem sua prova dos nove. É na rua que esse imaginário assume seu diálogo com o indeterminado a partir dos esbarrões e acidentes produzidos na grande metrópole: mente e acaso, como nos lembrou Ítalo Calvino (1990) no começo desde artigo. Ainda que a simulação impregnada no imaginário erguido pela cidade online, tal qual acontece nos games e plataformas interativas virtuais e reality shows, escreva suas cidades online, essas não estão dissociadas dos valores que são negociados no território do que entendemos como "cidade real".

Não é nosso propósito, neste texto, aprofundar a discussão acerca da dicotômica relação, comumente posta, entre um plano de realidade ou simulação, de real ou imaginário. Entretanto, sublinhamos que seja qual for a dimensão dessa realidade ela é sempre situada e co-dependente dos sujeitos que praticam suas cidades, lembrando do que nos diz Adriana Melo e Dina dos Santos (2008, p. 283284.): "O mundo denominado real se faz, portanto, dos diversos discursos sobre o que se denomina realidade, e esses discursos, por sua vez, se fazem dos olhos dos mais diversos sujeitos que experimentam o mundo, ou seja, da sua subjetividade". São ainda essas autoras que nos dizem que esse denominado "mundo real" e suas representações "[...] se constroem e se desconstroem ao 
longo do tempo, numa cartografia interativa e transitória, esfacelável e dinâmica (Melo; Santos, 2008, p. 284).

Assim, sem pretender extinguir a "realidade" da chamada cidade online, chamaremos essa outra cidade, mesmo com os riscos do termo, de cidade offline. Online ou offline, não nos restrinjamos a cindir em duas essas tantas cidades que coexistem na cidade fronteiriça. O que nos importa ressaltar é que tanto as cidades online afetam os ritmos e modos de vida das cidades offline, quanto essa cidade que se constrói offline "determina os ritmos das cidades imaginadas e define os estilos mesmo daqueles que imaginam uma independência original" (Sarlo, 2014, p. 210).

Nesta reflexão, não compreendemos o off como apagamento, como "desconexão", mas sim como outra faceta, outra perspectiva, dessa cidade fronteiriça. Tratamos então de evocar uma cidade/rua a ser novamente vivida, tracejada, percorrida, experimentada, ainda que de forma breve, mas com o wifi desligado. A cidade das ruas, das esquinas e proximidades não parou, como esperávamos em razão de tamanha pandemia. Nós, os que pudemos, é que sentimos como se tivéssemos perdido a rua. Mas de que é feita essa rua, essa cidade que chamamos aqui de offline?

Contraditória, plural, a cidade offline - abismo que nos chama - assegura o risco. Nela, o que há de certeiro é o erro, o obstinado convite para o tropeço. Se assim o for, esse abismo não poderia ser visto apenas de cima, como quem anuncia um mergulho (ou como quem tem nas mãos um GPS), mas topografado por baixo, como quem já se lançou à queda e não se surpreende mais com a vertigem ou com a desorientação. Na rua, o próprio precipício se torna corpo e, no seu frisson, ergue-se o perigo, quase mortal, de sua contingência, lembrando-nos que há abismos que valem mais que outros, e corpos que nunca sequer viram um paraquedas. "A cidade é, também, feita dessas contradições e, em muitas circunstâncias, se expressa através delas" (Hissa; Wstane, 2010, p. 86). As diversas dimensões desse corpo urbano, plural e contraditório, são tecidas por políticas de inclusão e exclusão, proximidades e distanciamentos, compartilhamentos os mais diversos. 
Estar vivo nessa cidade, nessa rua, nos faz falta. "Eu me experimento na cidade; a cidade existe por meio de minha experiência corporal. A cidade e meu corpo se complementam e se definem. Eu moro na cidade e a cidade mora em mim" (Pallasmaa, 2011, p. 38). Nosso corpo se faz corpo no mundo quando incorpora e é incorporado pelas ruas, cidades, vielas, e outras existências. Sobre o teatro que habitava a rua, podemos dizer que nos sentimos amputados.

Entretanto, estudos e debates aquecidos pelo contexto pandêmico nos apontam que o refúgio da cena teatral contemporânea é a rua, a silhueta urbana. Os prognósticos no campo do urbanismo seguem o rastro deixado por outras pandemias na história da humanidade para imaginar que é no espaço público que teremos a chance de reativar o contato com o outro, o convívio (Dubatti, 2012).

Citando Copenhagen, onde as escolas não possuem mais área de pátio fechada, a arquiteta e urbanista Ana Paula Wickert (2020) afirma que "algumas soluções já implantadas em outros países podem nos dar um direcionamento". As alternativas vivenciadas no espaço público no norte da Europa durante a crise sanitária da tuberculose no início do século 20 levou diversas escolas a adotarem a exposição ao ar fresco e à ventilação como medidas cabíveis ao enfrentamento da doença ${ }^{13}$.

Pensando no Brasil, com sua enorme diversidade de contextos, há outras nuances a serem levadas em conta nesse tipo de prognóstico. Entretanto, o que Wickert nos provoca a pensar é na viabilidade de operarmos uma gestão pública alinhada ao desenvolvimento de cidades que valorizem seus espaços públicos como territórios de sociabilidade e partilha, ou mesmo em ideias mais propositivas como a de "desenvolver um programa que fechasse uma série de ruas aos finais de semana para fluxo de veículos buscando ampliar o convívio social nos bairros." (Wickert, 2000).

Na busca por devolver às cidades o seu protagonismo, arquitetos e urbanistas têm proposto tangentes criativas para o contexto em que vivemos. De tal modo

${ }^{13}$ Para acessar imagens dessas escolas ao ar livre, acessar:

https://www.messynessychic.com/2016/03/15/classrooms-without-walls-a-forgotten-age-of-open-airschools/ 
que, se admitirmos nosso gesto de composição em arte como um dos passos que se dá na criação de nossas cidades, entenderíamos que mais que ao poder municipal e das prefeituras, ou mesmo às boas intenções do urbanismo, há matéria dinâmica sendo fervilhada em nossas práticas artísticas, seja pelo mover de imaginários e discursos ou mesmo por construir e manusear atmosferas no urbano. Não se trata, no entanto, de responsabilizar as artes sobre as municipalidades instituídas ou de saudar algum tipo de poder divino ou heroico dos artistas. Aqui, vislumbramos a possibilidade de pensarmos sobre quais gestos e imaginários estão sendo reiterados e tensionados em nossas práticas que, não podemos negar, também compõem as cidades.

Se, por um lado, admitimos que trazemos parcelas de rua para a cidade online quando agenciamos novos modos compositivos por intermédio de lives, vídeos ou registros compartilhados em larga escala, resta saber se por outro lado haverá mesmo, num mundo pós pandemia, um corpo e uma cidade essencialmente offline. Seria ilusório afirmar isso. "A caracterização sociodemográfica do espaço urbano não consegue dar conta de seus novos significados se não incluir também a recomposição que a ação midiática thes imprime" (Canclini, 2002, p. 41). Parece-nos, então, que somente uma dialética pendular pode se erguer como estratégica para a configuração de uma crítica capaz de não se perder nos domínios fetichistas e ostensivos da internet - pelo menos da forma como ela hoje existe - e ainda assim compor cidades offline que não recalquem sua pulsão virtualizada.

É possível que, no sonhado pós pandemia, o passado da experiência ostensiva de imersão na cibercidade apareça na memória como um sintoma de solidão e ansiedade e que a dimensão online seja inconscientemente internalizada como algo ligado a doença (Bernardi, 2020). Entretanto, não teremos mais como pensar a cidade sem levar em consideração o que foi forjado, imaginado, escrito, tecido, circunscrito, corporificado, na vida online.

Ao pensarmos a cidade como um emaranhado de corpos humanos e não humanos tecendo a vida urbana, não podemos esquecer que 
a questão do tipo de cidade que queremos não pode ser separada da questão do tipo de pessoas que queremos ser, que tipos de relações sociais buscamos, que relações com a natureza nos satisfazem mais, que estilo de vida desejamos levar, quais são nossos valores estéticos. (Harvey, 2014, p. 28).

Sendo o nosso corpo resultante da relação com a cidade - e entendendo a recíproca como verdadeira -, não poderemos esquecer do tempo "confinado" dentro de casa, das marcas da cidade offline na cidade online, dos olhares absortos e desejantes nas janelas, as quais, em disputa com as telas, ganharam status de território entre (Hissa, 2017) - espaço para vivermos o sonho que nos traria de volta ao transito on-off, dentro-fora; casa-rua. A tão esperada retomada de experiência plena com a cidade offline poderá estar impregnada de todas essas reminiscências. Se antes a rua era vista como o território do perigo e o lar um refúgio de amparos, é possível que essa premissa se borre nos alertando que haverá, no espaço público, algo que nos "salva", restituindo nossa intersubjetividade tecida pelos toques, esbarrões, odores e olhares. Tal como as escolas da Europa no século 20, talvez as artes habitem a cidade offline como lugar de refúgio para um sensível absorto e exausto da repetição enclausurada dos roteiros previstos dentro da casa e do apartamento.

Muitas cidades foram imaginadas e vividas nesse agora que se impôs. Consideramos que é nesse offline, sem desconsiderar sua pulsão on, que elas estarão sendo colocadas em pauta. Essas cidades que imaginamos não deixarão de ter "uma força e presença fundamentais na estruturação do funcionamento cotidiano das ruas, dos lugares públicos onde essa cidade se materializa" (Carreira, 2009, p. 12). Ao compreendermos isso, poderemos ver as artes da rua pulsando em sua maior potência, uma vez que são elas que

fornecem elementos que contribuem com a formulação de cidades imaginárias. Neste sentido, um teatro de ocupação se formula necessariamente como uma proposta que repensa esse imaginário que constitui a cidade como espaço desejado, sonhado, isto é, como um espaço a ser deformado pela ação da ficção. (Carreira, 2009, p. 12). 
Figura 1 - Performance de "Roof Piece" nos anos 1970, realizada nos telhados do SoHo Paula Cooper Gallery/New York Times

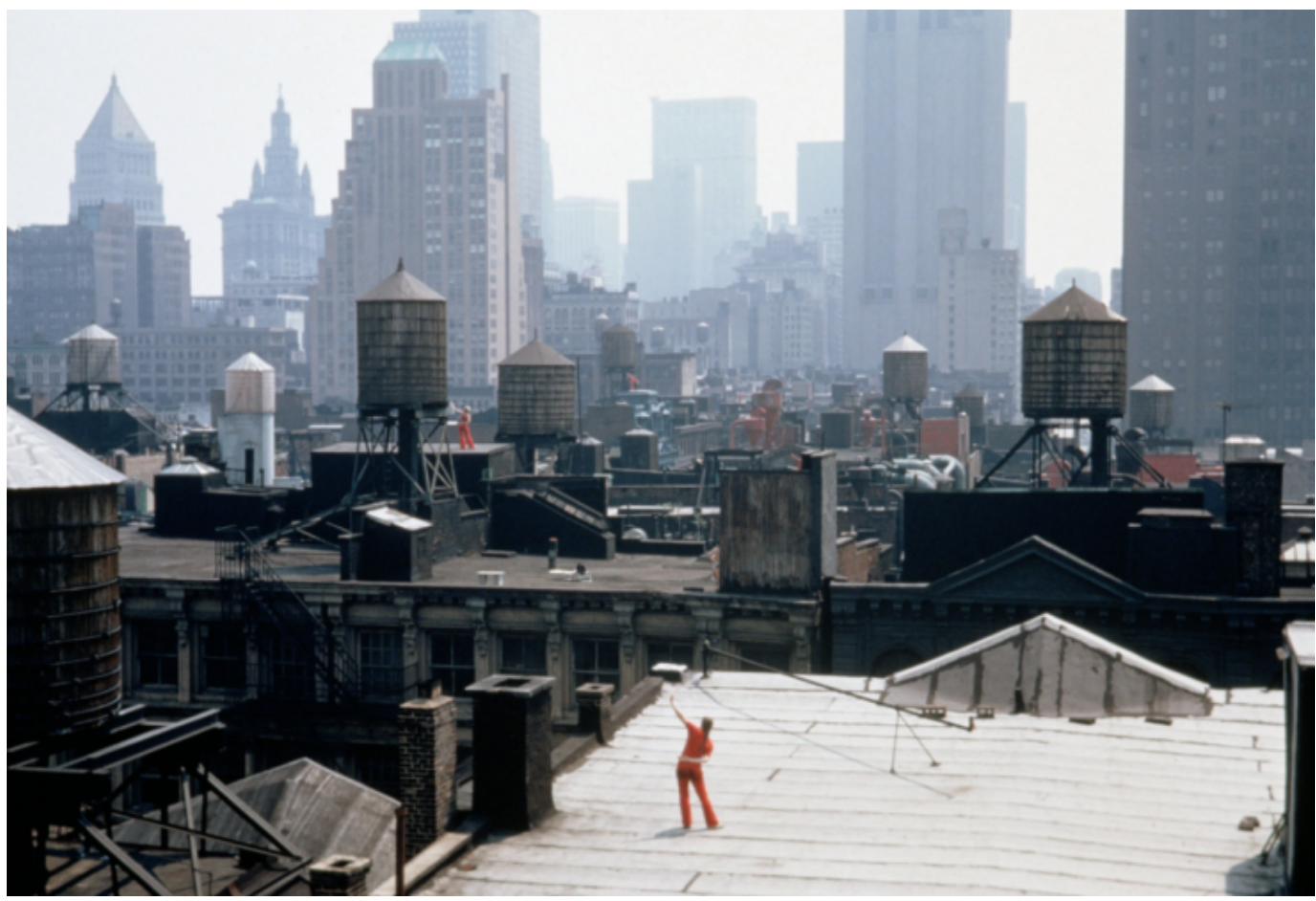

É na formação dessas novas ficções que a rua dos que ficaram em quarentena se reergue, seja na vida online ou mesmo fora da internet. É possível que as imagens comecem a subir pelas paredes ou que as artes da cena habitem topos de prédios, como o trabalho da Trisha Brown Dance Company e seu espetáculo Roof Piece (1971)14; ou aconteça nas janelas, como o espetáculo Esparrama pela Janela (2019) que, antes mesmo da pandemia, já realizava suas sessões nas janelas do Minhocão, em São Paulo'5; ou seja feito para um público muito restrito ou explorem os serviços de entrega ou drives-thru, como o espetáculo Die Methode (2020), da Cia Deutsches Theater de Göttingen

${ }^{14}$ No espetáculo, os bailarinos da companhia novaiorquina Trisha Brown Dance experimentavam o jogo do telefone sem fio. Instalados nos topos de prédios de Soho, entre as caixas d'água de Nova York. Os espectadores, também posicionados em topos de edifícios, acompanhavam os erros e acertos das repetições. Em 2020, a companhia experimentou uma versão online do trabalho, na qual, através do Zoom Clouding Meeting, transmitiam e experimentavam o mesmo gesto à distância.

${ }^{15}$ A peça conta a história de um morador do Minhocão (SP) que se vê cansado dos barulhos da cidade. Trazendo a experiência de arte e cidade também para o público infantil, o grupo apresentava seu "teatro na janela" desde 2013. Com a pandemia, até a data da publicação deste artigo, não aconteceram novas apresentações. 
(Alemanha), em que os espectadores veem cenas dentro dos seus carros e os atores também encontram-se confinados atrás (e dentro) dos vidros de carros, portarias ou cabines de teleférico ${ }^{16}$; ou que se utilize de dispositivos de microfonação que resgatem a tridimensionalidade do nosso corpo tão bidimensionado pela tela do smartphone, como em Poesia pra Vizinhança (2020), do cearense Alysson Lemos ${ }^{17}$; ou que se reviva a rua de longe, em cenas feitas em praças e ruas pouco ocupadas, com encenações transmitidas do espaço público, à distância, como o fizeram os coletivos \#Joyces, Plataforma Beijo e Escola Indisciplinada no experimento Território Escola (2020)18; ou se criem novas radionovelas e outros dispositivos de comunicação analógicos, como propôs o Grupo Magiluth (PE) em sua obra Tudo que coube numa VHS (2020)19; ou que se elaborem novas técnicas e tecnologias para garantir a distância mínima para mitigar a exposição ao vírus, tecendo uma cidade que, mais que imaginada pelo meio, consiga produzir novos meios para imaginar a vida. As experiências vividas e imaginadas com o tempo-espaço têm se ampliado de tal forma que podemos nos perguntar: deixamos a rua para construir esses novos possíveis - janelas, prédios, ruas vazias, telhados, carros?

\footnotetext{
${ }^{16}$ Baseado na peça "Corpus Delicti” de Juli Zeh, o grupo alemão Deutsches Theater Göttingen realiza um teatro drive-thru. Segundo o site do grupo (https://www.dt-goettingen.de/stueck/die-methode/), "os visitantes seguem em seu carro um percurso pelo estacionamento subterrâneo do teatro e param em quatro locais, onde cada um encontra uma figura tão isolada quanto eles em seus veículos. Atores e público estão no mesmo espaço, separados pela caixa que os rodeia, mas obrigados a passar algum tempo juntos." (Die Methode, 2020, tradução nossa).
}

17 Poemas, textos e manifestos cedidos por pessoas do Ceará constituem o trabalho do artista Alysson Lemos que realiza leituras livres com caixas amplificadas na janela de seu condomínio durante o isolamento social.

${ }^{18}$ Quase seis meses depois do anúncio da pandemia da Covid-19, três coletivos de artistas e educadores de Belo Horizonte se encontram nesse experimento, com direção de Altemar Di Monteiro, para pensar a rua como um território-escola, lugar onde a arte e a educação se fundem. A imagem das escolas ao ar livre durante a pandemia da tuberculose, na Europa, anteriormente referidas neste texto, instiga os artistas a experimentar cenas na rua, em praças vazias ou pouco movimentadas. Os artistas se encontram via Zoom e produzem sua cena no espaço público, garantindo o distanciamento recomendado e as ferramentas de proteção sanitária: as máscaras, luvas e outros equipamentos de arqueologia são fundamento para a dramaturgia, para a encenação e para a proteção dos envolvidos. A cena acontece on e offline: para um público da rua que acompanha à distância cada ator na praça visitada e para outro público que, em casa, assiste a transmissão via Zoom.

${ }^{19}$ O grupo pernambucano Magiluth tem experimentado a cena para além da produção de lives. Tudo o Que Coube numa VHS conta uma narrativa através de fragmentos em várias plataformas, como mensagens de WhatsApp, músicas, vídeos, e-mails e ligações telefônicas. Todas as histórias possíveis, segundo experimento do grupo durante a pandemia, também explorou esse formato. 
Figura 2 - "Esparrama pela Janela", Grupo Esparrama (SP). Foto: Sissy Eiko

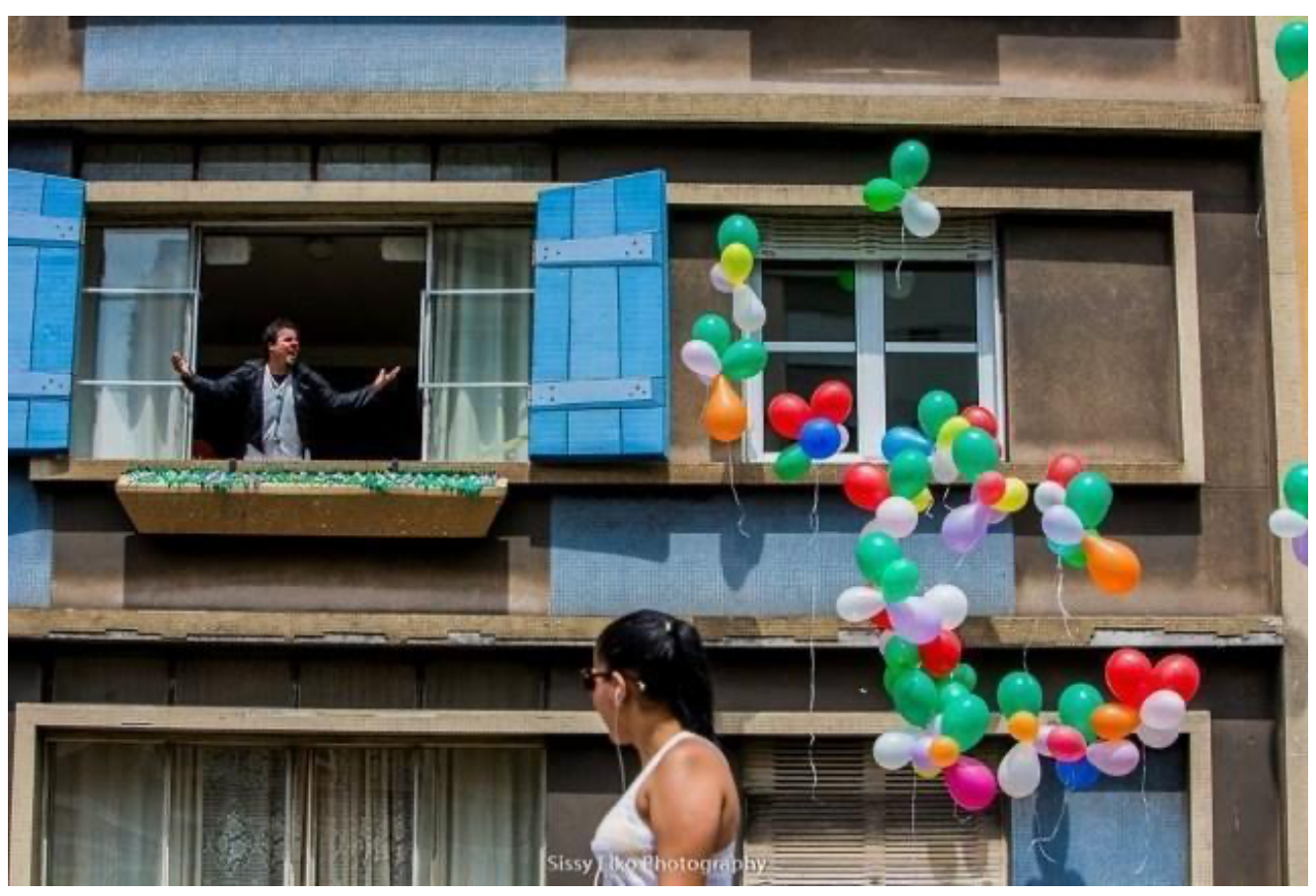

Figura 3 - Die Methode, Cia Deutsches Theater de Göttingen (Alemanha). Foto: Thomas M. Jauk

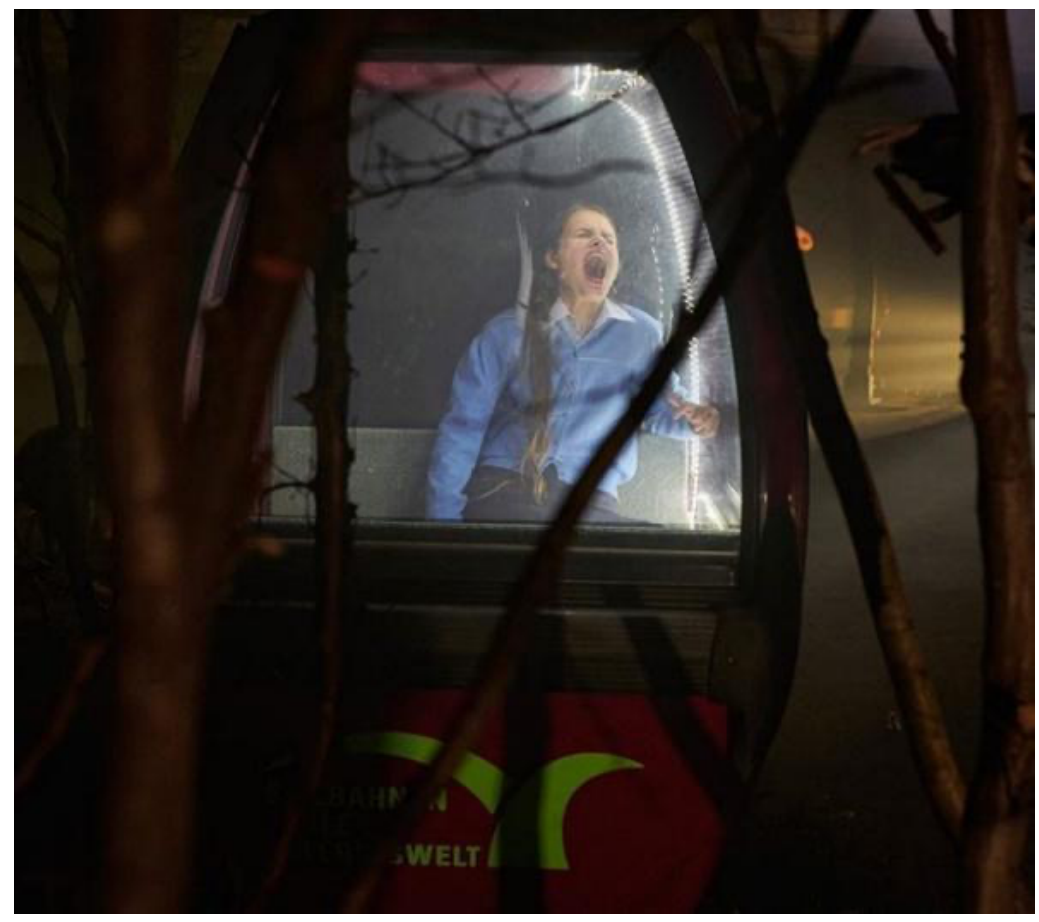

Fonte: Instagram @ deutschestheatergoettingen 
Trabalhos, como os citados acima, apontam os diversos atravessamentos on e offline, levando-nos a ver que tais instâncias que poderiam, à primeira vista, parecer cindidas, não estão. Ainda que não tenham a internet como principal meio para a sua realização, são práticas cênicas que interferem nos imaginários, nos processos de composição das cidades, reverberando nas redes de silício e nas vias urbanas. Se, antes da pandemia, a produção cultural já compreendia os meios de comunicação como força ativa para a mobilização de recursos humanos e não humanos, talvez seja agora que se torne mais nítido o quanto tais dinâmicas e dispositivos interferem nos processos de criação, na sua composição e recepção das próprias obras artísticas. Uma atenção profunda aos meandros de nossas escolhas e gestos compositivos é que pode nos levar a uma análise sobre nossos desafios, compromissos e responsabilidades éticas e estéticas sobre o mundo que já se faz hoje e aqui.

Figura 4 - Alysson Lemos (CE)

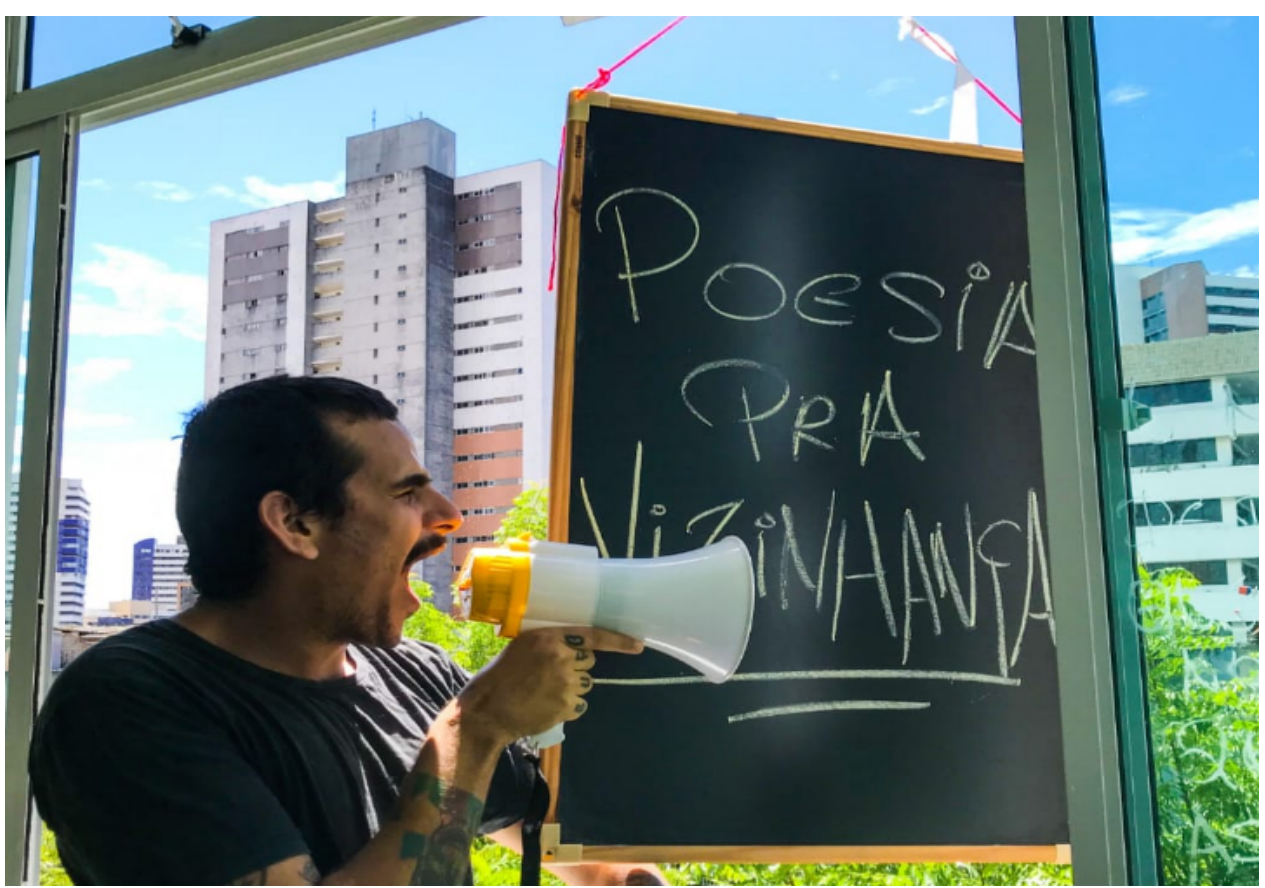

Fonte: Arquivo pessoal do artista 
Figura 5 - Frame da exibição de "Território Escola" - \#Joyces

Plataforma Beijo e Escola Indisciplinada (MG)

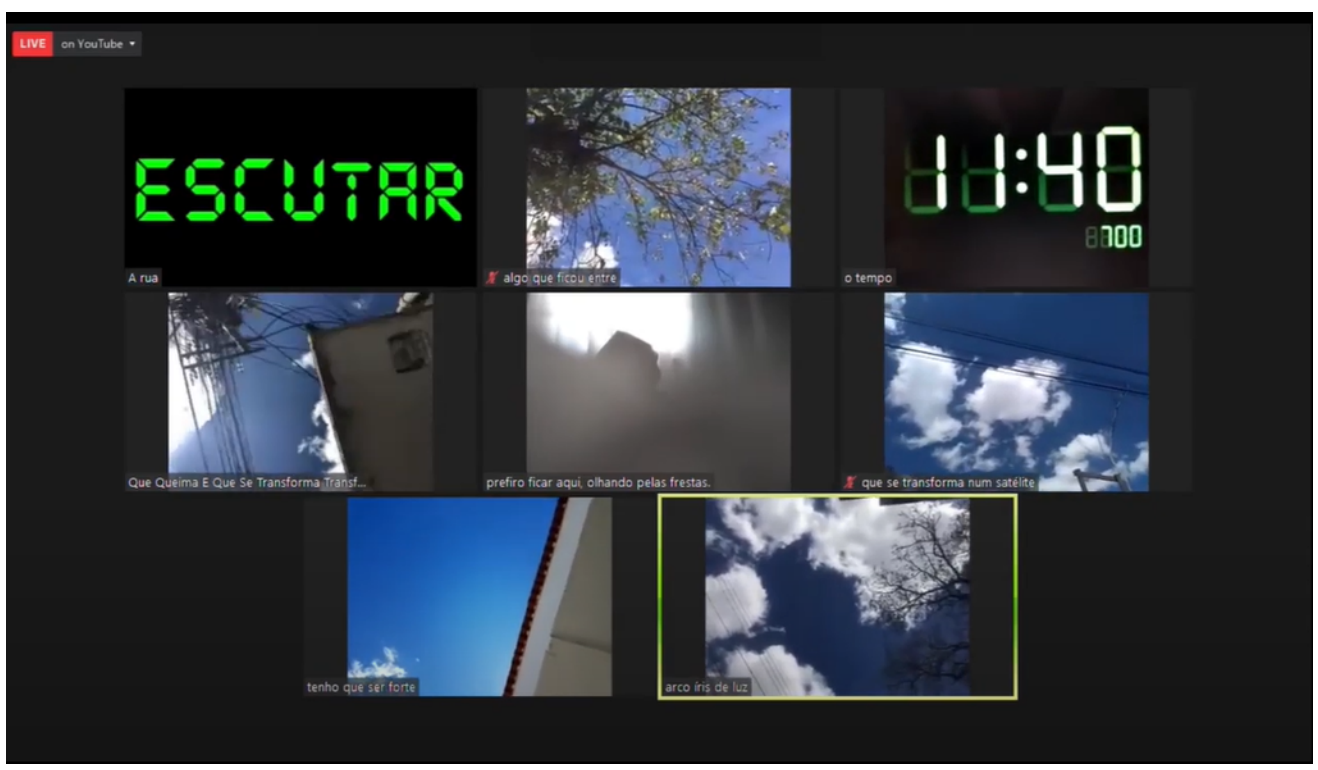

Fonte: Arquivo dos coletivos

\section{Considerações finais ou as Cidades em Precipício}

Muitas cidades estão sendo compostas nesse agora da pandemia: a cidade dos que a sonham desde suas casas, a cibercidade, a cidade online impregnada de off-line, a cidade segura, a cidade imaginada, as cidades possíveis de um futuro mais que esperado. Podemos pensar, inclusive, na possibilidade de que tudo aqui referimo-nos às cidades e ruas, espaços de cena - continue como antes da pandemia. Entretanto, não teremos como negar os efeitos dos imaginários vivenciados, das ficções reativadas, dos desejos recalcados, das violências experimentadas no que se propõe de relação com as ruas e com o espaço público. Nem tão pouco teremos como negar que nesses projetos teatrais quase sempre há uma ou várias cidades sendo excluídas: seus públicos-alvo recaem na relevância das discussões sobre acesso e democratização aos bens da Cultura.

Mas a cidade é sempre território fronteiriço, que se abre ao diverso, ao plural, ainda que sob cerceamento de governos e políticas de exclusão. Reiteramos, 
então, a necessidade de se compreender a condição fronteiriça desse território também das artes da cena, do teatro com a rua. Assim, não estaríamos falando de um antes, onde a rua era plena, nem tampouco de um presente, no qual perdemos a rua. Falamos de um ethos que se faz necessariamente no território da fronteira, e tão somente nele. Ainda que em casa, trazemos a cidade em nós ao compormos cidades online. Ainda que imersos na rede, trazemos as marcas dos perigos e riscos da cidade off-line. Esses, inclusive, adentraram nossos lares por meio de assaltos, haqueios e outros males que não se fundam nos territórios on ou off, mas no humano. Portanto, pensar a cidade como fronteira, pensar que a cidade se precipita implica pensar na ética dos gestos com os quais compomos a cidade por meio da arte e, também, na urgente necessidade de nos compreendermos como corpos de relação, corpos de contato, corpos de convívio. Apontamos, então, a arte que se faz com a cidade, com a rua, como campo expandido de entrelaçamentos os mais diversos que se direcionam para uma existência compartilhada.

Uma vez praticados espaços teatrais outros, como as janelas, os carros, os telhados, valorizado as sonoridades e os olhos fechados à distância, que tipo de rua nos espera? Corpos online despontam no espaço público desde antes da pandemia. Talvez mais que antes, nosso trabalho de composição em arte exija uma atenção às violências das forças on e offline, entendendo que não haverá paz ou mansidão que neguem que o mundo está em mutação, e que é sob o custo de muitos erros e acertos que adentraremos novamente às possibilidades de invenção de novos corpos e cidades. Das fronteiras que se avistam no amálgama dessas cidades surge o desejo de não mais negar a força política da imaginação, abraçando-a como matéria movente no que já existe e no que vem.

Um teatro fronteiriço, que sentiu a dor do mergulho profundo nas redes complexas da internet, não abandonará facilmente a possibilidade de perceber os meios de comunicação não mais apenas como instrumento, como publicidade, como arquivo, como correio, como telefone, como game, mas também, ou mais ainda, como dispositivos que não só interferem, mas alimentam nossos processos de composição de dramaturgia e de encenação. 
Especulações em precipício, diríamos. E como precipício, exige que abandonemos os acúmulos, que lancemos fora as arestas do conformismo, as violências da subserviência, as manias embrutecidas do consumo, as justificativas ensaiadas para a negação de qualquer risco, os desejos inconformados de mais e mais informação. Lança tudo por baixo para se jogar de novo à rua, à vertigem, lançando-se ao indeterminado, ao por vir que se anuncia por corpos que, em noites frias de abandono, alimentaram os seus mais profundos anseios. Sonhamos e desejamos um corpo e uma cidade que não sucumbam a unidades imaginárias encerradas em figuras de soberania, em narrativas e possibilidades unas. Por "um corpo social des-idêntico e inquieto, em vez do corpo unitário do imaginário social" (Safatle, 2015, p. 94). Por um agora como força movente no corpo e na cidade, não para um hedonismo fetichizado e higiênico, mas para o compromisso com a vida, com o que ela ativa de terror e ternura, com o que ela evidencia de paixão e nãosaber. Para que possamos divinare, como nos falava Manuel de Barros, e, como sabiás, não apenas topografar o acidente que nos espera, mas alçar voo frente ao abismo.

Figura 6 - "Saut dans le vide". Yves Klein

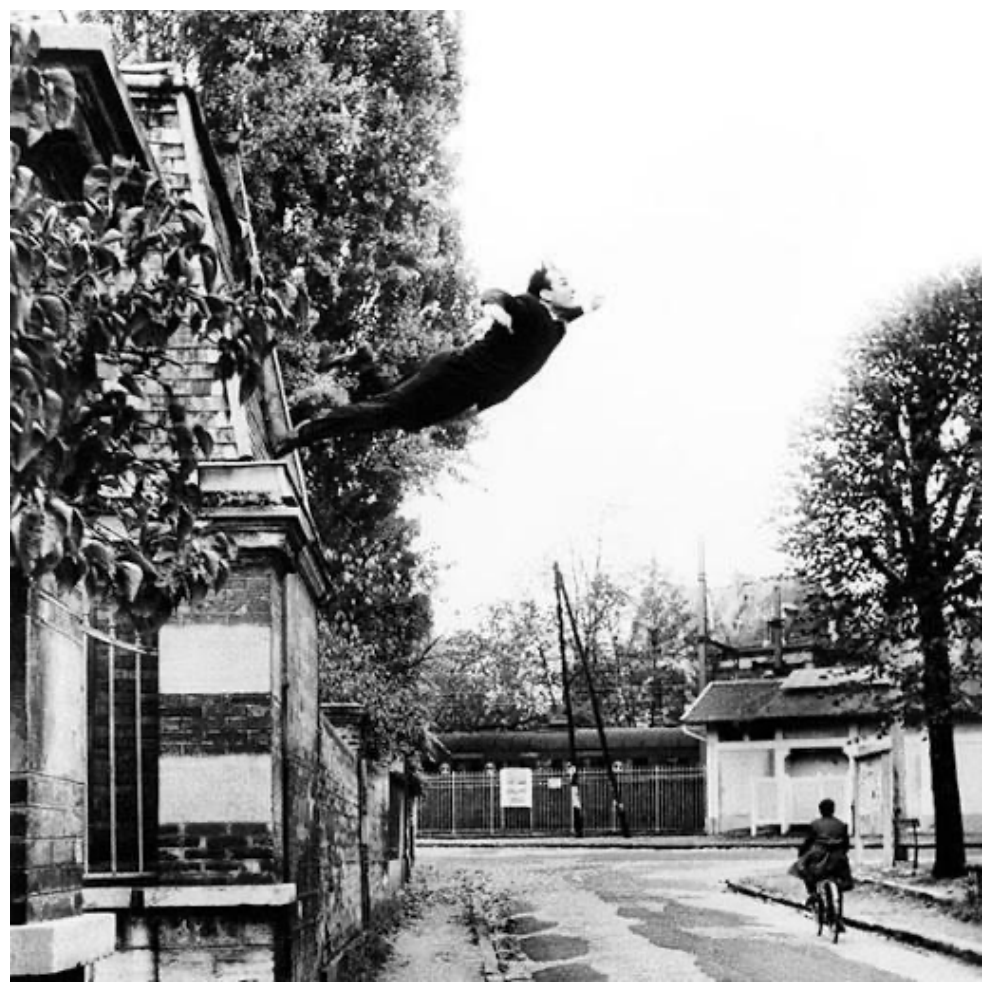




\section{Referências}

ABBAGNANO, Nicola. Agora. In: Dicionário de Filosofia. São Paulo: Martins Fontes, 2018, p. 23.

BENNATON, Pedro. O teatro como respirador social: reflexões sobre arte presencial na pandemia. Portal Descato.info. 02 de maio de 2020. Disponível em: http://desacato.info/o-teatro-como-respirador-social-reflexoes-sobre-artepresencial-na-pandemia/. Acesso em: 29 jun. 2020

BERARDI, Franco. "A pandemia reativou o futuro. Há condições para reformatar a mente social". Entrevista concedida a Luisa Duarte e Victor Gorgulho. Jornal El País, São Paulo, 03 de junho de 2020. Disponível em: https://brasil.elpais.com/cultura/2020-06-02/franco-berardi-a-pandemiareativou-o-futuro-vejo-condicoes-para-a-reformatacao-igualitaria-da-mentesocial.html. Acesso em: 29 jun. 2020

CALVINO, Ítalo. As Cidades Invisíveis. São Paulo: Cia das Letras, 1990.

CANCLINI, Néstor García. Cidades e cidadãos imaginados pelos meios de comunicação. Campinas: Revista Opinião Pública, 2002

CARREIRA, André. Teatro de rua como ocupação da Cidade: Criando Comunidades Transitórias. Urdimento, Florianópolis, v. 1, n. 13, 2009.

DIE Methode. Nach dem Stück "Corpus Delicti" von Juli Zeh. Disponível em https://www.dt-goettingen.de/stueck/die-methode/. Acesso em: 30 jun. 2020

DUBATTI, Jorge. Teatro, convívio e tecnovívio. In: CARREIRA, André; BIÃO, Armindo; TORRES NETO, Walter (org). Da Cena Contemporânea. Porto Alegre: ABRACE, 2012

DUBATTI, Jorge. Artes conviviales y Artes tecnoviviales: estudiar y enseñar en el actual contexto. In: Fórum de Estágios - Docência em Teatro - 1a Edição/2020, da UFSM, UFPEL, URGS, UERGS, ${ }^{\circ}$, 2020. Palestra proferida em 14 de agosto de 2020, às $15 \mathrm{~h} 00 \mathrm{~min}$

HARDT, Michel; NEGRI, Antonio. Multidão: guerra e democracia na era do Império. Rio de Janeiro: Record, 2005

HARVEY, David. Cidades Rebeldes. Do direito à cidade à revolução urbana. São Paulo, Martins Fontes, 2014.

HISSA, Cássio Eduardo Viana. A mobilidade das fronteiras: inserções da geografia na crise da modernidade. 1a reimpressão. Belo Horizonte: Ed. UFMG, 2006.

HISSA, Cássio E.V. Cidade e ambiente: dicotomias e transversalidades. In: HISSA, 
Cássio E. V. Saberes ambientais: desafios para o conhecimento disciplinar. Belo Horizonte: editora UFMG, 2008.

HISSA, Cássio E.V.; WSTANE, Carla. Cidades Incapazes. GEOgraphia, 2010.

HISSA, Cássio E. Viana. Transdisciplinaridade: breves notas acerca de limites e fronteiras da ciência moderna. TERCEIRO INCLUÍDO, NUPEAT-IESA-UFG, v.1, n.1, jan./jun., 2011, p.90-105,

HISSA, Cássio E. Viana. Entre. In: SILVA, Maria Ivonete Santos; MOREIRA, Maria Elisa Rodrigues (Org.). Literatura: espaço fronteiriço. Colatina; Chicago: Clock Book, 2017.

INGOLD, Tim. Estar Vivo: ensaios sobre movimento, conhecimento e descrição. Coleção Antropologia. Petrópolis: Vozes, 2015.

LAZZARATO, M. As Revoluções do Capitalismo. Rio de Janeiro: Civilização Brasileira, 2006.

MELO, Adriana Ferreira de; SANTOS, Diana Maria dos. Cidade e escritura: cartografias do transitório. In: HISSA, Cássio E. V. Saberes ambientais: desafios para o conhecimento disciplinar. Belo Horizonte: Editora UFMG, 2008.

MESSYNESSY. Classrooms without Walls: A Forgotten Age of Open-air Schools. Disponível em: https://www.messynessychic.com/2016/03/15/classroomswithout-walls-a-forgotten-age-of-open-air-schools/. Acesso em: 30 jun. 2020.

MUNIZ, Mariana; DUBATTI, Jorge. Cena de Exceção: o teatro neotecnológico em Belo Horizonte (Brasil) e Buenos Aires (Argentina). Revista Brasileira de Estudos da Presença, vol.8 no.2 Porto Alegre, 2018.

PALLASMAA, Juhani. Os olhos da pele: a arquitetura e os sentidos. Porto alegre: Bookman, 2011.

SAFATLE, Vladimir. Circuito dos Afetos: Corpos políticos, Desamparo, Fim do Indivíduo. São Paulo: Cosac Naify, 2015.

SARLO, Beatriz. A cidade vista: mercadorias e cultura urbana. São Paulo: Editora WMF Martins Fontes, 2014.

STENGERS, Isabelle. No tempo das catástrofes. São Paulo, Cosac Naify, 2015

WICKERT, Ana Paula. Como a pandemia de COVID-19 vai nos desafiar a criar novos espaços públicos. ArchDaily Brasil, 18 de abril de 2020. Disponível em: https://www.archdaily.com.br/br/937529/como-a-pandemia-de-covid-19-vainos-desafiar-a-criar-novos-espacos-publicos. Acesso em: 29 jun. 2020 
Recebido em: 30/06/2020

Aprovado em:03/09/2020

Universidade do Estado de Santa Catarina - UDESC Programa de Pós-Graduação em Teatro - PPGT Centro de Arte - CEART Urdimento - Revista de Estudos em Artes Cênicas Urdimento.ceart@udesc.br 